\title{
Emerging techniques in food science: the resistance of chlorpyrifos pesticide pollution against arc
}

\section{and dielectric barrier discharge plasma}

\author{
Mohsen Gavahian ${ }^{1, *}$, Tsai Meng-Jen ${ }^{2}$, Amin Mousavi Khaneghah ${ }^{3, *}$ \\ ${ }^{1}$ Department of Food Science, National Pingtung University of Science and Technology, Pingtung 91201, Taiwan, ROC; \\ ${ }^{2}$ Product and Process Research Center, Food Industry Research and Development Institute, Hsinchu, 30062, Taiwan, \\ ROC; ${ }^{3}$ Department of Food Science, University of Campinas, Campinas - SP, Brazil
}

"Corresponding Authors: Mohsen Gavahian, Ph.D., Department of Food Science, National Pingtung University of Science and Technology, Pingtung 91201, Taiwan, ROC. Email: mohsengavahian@yahoo.com; Amin Mousavi Khaneghah, Ph.D., Department of Food Science, Faculty of Food Engineering, University of Campinas (UNICAMP), Rua Monteiro Lobato, 80. Caixa Postal: 6121.CEP: 13083-862, Campinas, São Paulo, Brazil. Email: mousavi@unicamp.br

Received: 01 September 2020; Accepted: 28 September 2020; Published: 14 October 2020 (C) 2020 Codon Publications

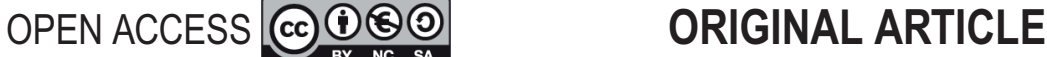

\begin{abstract}
Many studies introduced cold plasma as a novel and effective processing technology for microbial decontamination of food and water as well as for the removal of environmental pollution such as pesticide. However, as there are several types of plasma designs, their efficacy in degrading major pesticide residues, such as chlorpyrifos (as a hazardous chemical), should be explored. This study was conducted to assess the decontamination efficacy of $8 \mathrm{~min}$ of arc and dielectric barrier discharge (DBD) plasma on chlorpyrifos pesticide-water samples at a concentration of $2 \mathrm{mg} \cdot \mathrm{L}^{-1}$. The plasma-treated samples were assessed by liquid chromatography-mass spectrometry (LC-MS) and compared with the control (untreated) sample. In addition, the effects of plasma processes on some physical properties of samples were studied. According to the results, plasma-treated samples showed similar physical characteristics (e.g., refractive index and color values) to those of the untreated samples. While the temperature of the samples remained steady during the DBD plasma treatment, arc plasma changed the temperature of the sample at a rate of about $3.75^{\circ} \mathrm{C} \cdot \mathrm{min}^{-1}$ and yielded a sample with a final temperature of $60^{\circ} \mathrm{C}$. However, contrary to the general belief that plasma is an efficient technique for pesticide degradation, chemical analyses showed high resistance of chlorpyrifos against both arc and DBD plasma under the conditions used in the present study. Therefore, the possibility of high resistance of pesticide pollution to this emerging technology should be considered. Also, further studies on the efficiency of the selected plasma system for removing pesticide pollution (e.g., during water and wastewater treatment) at industrial scale is needed.
\end{abstract}

Keywords: decontamination; emerging processing technology; hazardous chemical; nonthermal plasma; pesticide pollution, pesticide reduction

\section{Introduction}

The agricultural industry utilizes the approaches that stabilize the production rate and avoid economic loss unpleasant phenomena such as pest attack (Halimatunsadiah et al., 2016). For example, many farmers may use approved chemical pesticides in accordance with regulations (Guo et al., 2020; Heshmati et al., 2020). However, many environmental scientists warned about the negative effects of these contaminants because they act as environmental pollutants that pose negative health effects (Albasher et al., 2020; Ali et al., 2020). Food scientists also warned about the safety aspects of the agricultural products that contain pesticide residues (Serefoglu and Serefoglu, 
2016). For instance, chlorpyrifos (O, O-diethyl-O-3,5,6trichlor2-pyridyl phosphorothioate) has been widely employed in the agricultural industry for controlling a variety of crop pests, including white-ants and foliar insects, for more than half a century. According to the United States Environmental Protection Agency (EPA), direct food exposure of this pesticide for children is about $0.24\left(\mu \mathrm{g} \cdot \mathrm{kg}^{-1} \cdot \mathrm{day}^{-1}\right)(\mathrm{EPA}, 2016)$. Also, a tolerance level of $100 \mathrm{ppb}$ is defined for chlorpyrifos residues, per se, in or on food commodities (Regulations, 2020). It was revealed that consumption of the residues of this chemical can result in diarrhea, frequent urination, abnormal sweating, salivation, lacrimation, genotoxicity, neurochemical changes, neurobehavioral disorder, and abnormal birth outcomes (Anderson et al., 2018; Farkhondeh et al., 2020; Foong et al., 2020). Therefore, its indoor application was banned by EPA since the early 21st century. However, it is still among the most widely used and approved pesticides in the agriculture industry, with an annual consumption of about 4,000,000 kg in the United States (EPA, 2011a, 2011b). This health-threatening pesticide is also authorized for agricultural applications in many countries (Foong et al., 2020; Razzaghi et al., 2018).

Besides, food regulations can vary across regions, and insufficient attention of regulatory bodies in some developing countries may result in agricultural products that cannot comply with the food safety regulations of the importing country (e.g., due to high concentrations of pesticide residue). Therefore, the presence of chemical pesticide residues is challenging the agro-food industry. In this regard, scientists tried to develop effective approaches for the production of pesticide-free agricultural and food products by exploring the efficacy of decontamination techniques such as photocatalysis (Vigneshwaran et al., 2019) and ultrasound treatment (Jawale and Gogate, 2016), and ozone (Pandiselvam et al., 2020). However, none of the proposed methods satisfied the industry due to the production of unwanted by-products or low efficiency. Recently, cold plasma, which is a combination of electrons, photons, ions, free radicals, and other reactive species, has been introduced to the food industry, and it showed several potential applications, including pesticide degradation (Gavahian and Cullen, 2020; Gavahian and Khaneghah, 2020; Sarangapani et al., 2016). Besides, sustainability and sustainable development get attention from various industries (e.g., food and agriculture industry) in many regions of the world. For example, the central ministries of Taiwan, including EPA, Council of Agriculture (COA), and the Ministry of Economic Affairs (MOEA), have supported the regulatory promotion. In agreement with the sustainable development goals (SDGs) launched in Taiwan, it seems that cold plasma, specifically the application of this green technology for the sustainable decontamination of food, water, and wastewater, has the capacity to help in meeting the SDGs. A wide range of designs has been proposed for plasma applications in the food industry, such as arc, dielectric barrier discharge (DBD), glow, in-pack, and corona discharge, which necessitates exploring their performance in the production of pesticide-free products. Many studies introduced plasma as a promising tool for pesticide degradations. However, reports on the possible resistance of pesticides against plasma treatments are rare. Therefore, the present study aims to assess the feasibility of decontamination of chlorpyrifos, as a major pesticide residue in agricultural products, through DBD and arc plasma treatments.

\section{Material and Methods}

Figure 1 represents a summary of the methods used in the present study.

\section{Chemicals}

All the reagents were analytical grade and were obtained from Sigma-Aldrich (Missouri, United States). CAS 2921-88-2 (Chlorpyrifos pesticide) at a purity of 40.8 (w/w)\% was procured from Chia-yi Chemical Industry Corporation (Tainan, Taiwan).

\section{Pesticide preparation}

A mixture of pesticide (as described in the "chemicals section") in methanol prepared at $0.5 \mathrm{mg} \cdot \mathrm{mL}^{-1}$ was diluted with distilled water to the concentration of $2 \mathrm{mg} \cdot \mathrm{L}^{-1}$ (Sarangapani et al., 2016). The mixture was subjected to an electromagnetic stirrer to ensure that the pesticide is distributed thoroughly within the liquid phase.

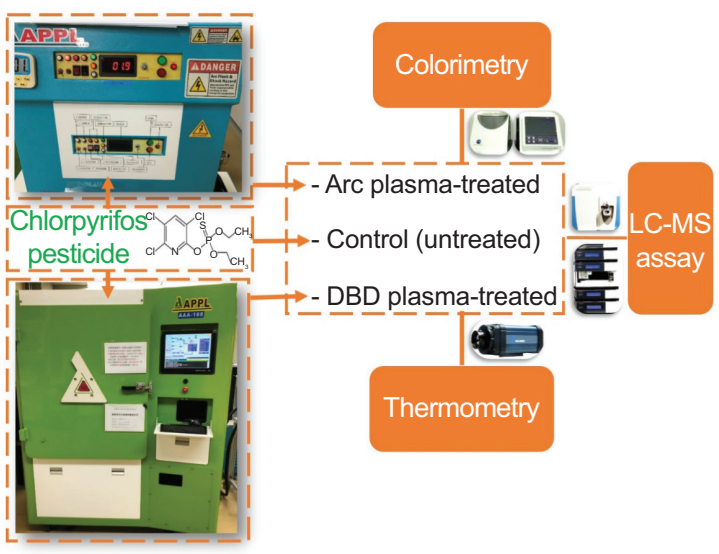

Figure 1. A graphical abstract representing the methods used in this study. 


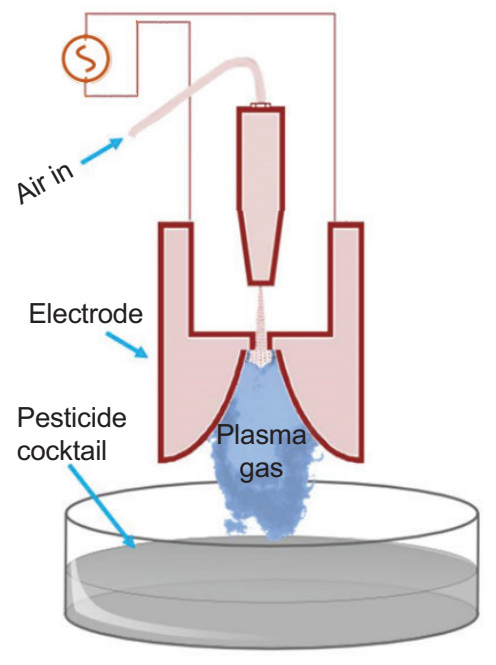

(a)

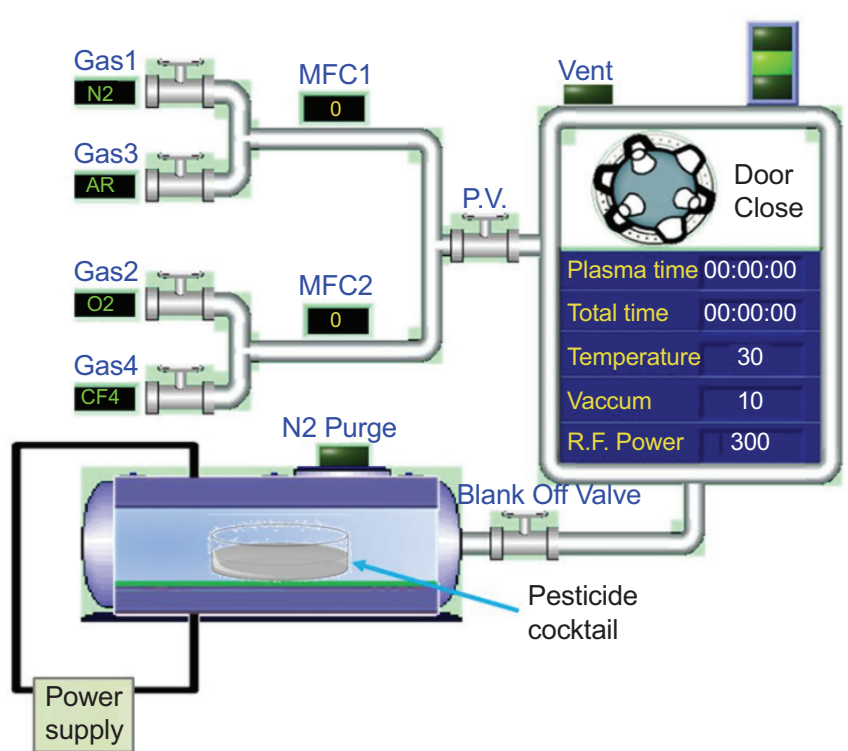

(b)

Figure 2. The schematic representation of the plasma devices employed in the present investigation: arc plasma (a) and dielectric barrier discharge (DBD) plasma (b).

\section{Plasma equipment and process parameters}

DBD and arc plasma devices were employed in the present work (Figure 2). Table 1 represents the process conditions of these plasma systems. For DBD plasma treatment, AAA-168 DBD plasma (APPL, Taiwan) was employed at a constant temperature of $30^{\circ} \mathrm{C}$, which used nitrogen purity of $99.99 \%$ (Chiah Lung Enterprise Co., Taiwan) as the carrier gas. The pesticide sample $(20 \mathrm{~mL})$ was poured in a glass Petri dish $(100 \times 15 \mathrm{~mm})$ to form a thin layer. It was then placed in the discharging area of the DBD plasma. More details about the DBD system used in the present study can be found in a previous publication (Gavahian et al., 2020). Likewise, the same amount of pesticide sample was subjected to arc atmospheric-pressure plasma (APPL-10k, Taiwan) with a working distance of $5 \mathrm{~cm}$. More details about the arc plasma system used in the present study can be found in a previous publication (Gavahian et al., 2019b). The variations in the temperature of the sample during arc and DBD treatments were monitored through the TES 1306 thermometer (TES Electric Electronic Corp., Taiwan) and matching software (APPL, Taiwan), respectively. Both DBD and arc plasma treatments were applied for 8 min at a power of $0.3 \mathrm{~kW}$ in triplicate. This processing time was selected according to our preliminary study. Long processing times (e.g., 10 min) resulted in high temperatures of the sample in the arc system, which may degrade the pesticide, and such a degradation may be a reason for the misinterpretation of degradation data. The DBD-treated, arc-treated, and control (not treated by plasma) samples were kept in a dark and cool place before further studies.
Table 1. Arc and DBD plasma process conditions in this study.

\begin{tabular}{lcc} 
& DBD* plasma & Arc plasma \\
\hline Input gas & Nitrogen & Atmospheric air \\
Pressure $(\mathrm{kPa})$ & 10 & 101 \\
Process duration $(\mathrm{min})$ & 8 & 8 \\
Temperature $\left({ }^{\circ} \mathrm{C}\right)$ & 30 & $30 \sim 60$ \\
Input power $(\mathrm{W})$ & 300 & 300 \\
\hline \multirow{2}{*}{$\mathrm{DBD}$, dielectric barrier discharge. } & &
\end{tabular}

\section{Qualitative analysis of the pesticide residue}

The chemical composition of the samples was explored by liquid chromatography-mass spectrometry (LC-MS) to identify the possibly degraded products of pesticide and the concentration of the remaining pesticide in the plasma-treated samples in comparison with the control sample according to the procedure that was previously explained by Shoeibi et al. (2013). Briefly, $5 \mathrm{~g}$ of each pesticide sample, that is, control, arc plasma-treated, or DBD plasmatreated, was mixed with distilled water $(10 \mathrm{~mL})$ and acetonitrile $(10 \mathrm{~mL})$ in a centrifuge tube with the capacity of $50 \mathrm{~mL}$. Afterward, sodium chloride $(1 \mathrm{~g})$ and magnesium sulfate anhydrous (4 g) were added, which were vigorously shaken manually for $1 \mathrm{~min}$ before being centrifuged at $3500 \mathrm{rpm}$ for $10 \mathrm{~min}$. The supernatant was collected and passed through a nylon syringe filter that had a mesh size of $0.22 \mu \mathrm{m}$. The filtered liquid was subjected to LC-MS investigations. Hypersil Gold C-18 aQ (Thermo Scientific, USA) with the dimensions of $100 \times 2.1 \mathrm{~mm}$ and an internal 
diameter of $2.6 \mu \mathrm{m}$ was employed as the analytical column. Two mobile phases, that is, A and B, were used in the present work. The first one (mobile phase A) consists of ammonium formate (AF) with a concentration of $5 \mathrm{mM}$ and $0.1 \%$ formic acid (FA) in the water while the latter (mobile phase B) contained AF $5 \mathrm{mM}$ and $0.1 \%$ FA in methyl alcohol. The gradient elution program was as follows: $0-0.5 \mathrm{~min}(2 \% \mathrm{~B})$, 0.5-2 min (2-40\% B), 2-20 min (40-95\% B), 20-22 min (at $95 \%$ B), $22.0-22.1$ min (returned to $2 \%$ B), and allowed for equilibration for $180 \mathrm{~s}$ before the next injection. A constant flow rate of $300 \mu \mathrm{L} \cdot \mathrm{min}^{-1}$ was used in the LC assessment. For HESI-MS, pure nitrogen was used as both auxiliary and sheath gas. The spray voltage of positive ionization mode was set at $3.5 \mathrm{kV}$. In addition, the temperatures of the capillary and auxiliary gas heaters were 320 and $350^{\circ} \mathrm{C}$, respectively. The flow rate of the sheath and auxiliary gas were 40 and 10, respectively. Data collection was performed over an $\mathrm{m} / \mathrm{z}$ range of 100 to 1000 . Data independent was conducted at the normalized collision energy of 30 and $80 \mathrm{eV}$. The version 3.3 of TraceFinder (Thermo Scientific, USA) was used for processing the results.

\section{Refractive index evaluation}

A laboratory $\quad 0.0-33.0 \%$ Master-M Refractometer (ATAGO, Japan) along with the conversion table was employed for reflective index measurements. In this regard, samples were shaken, and $1 \mathrm{~mL}$ of the sample was placed on the daylight plate of the refractometer to obtain the results.

\section{Color of the pesticide}

The color of the pesticide was assessed through a CM-5 colorimeter (Konica Minolta Sensing, Japan) to obtain L*, $a^{*}$, and $b^{*}$ values, which represent the lightness, greenness-redness, and blueness-yellowness of the sample, respectively (Gavahian et al., 2012). In addition, the variations in the overall color of the plasma-treated samples in comparison with the control sample were calculated through Eq. (1) (Gavahian et al., 2019a).

$$
\Delta E=\sqrt{\left(L_{p}^{*}-L_{c}^{*}\right)^{2}+\left(a_{p}^{*}-a_{c}^{*}\right)^{2}+\left(b_{p}^{*}-b_{c}^{*}\right)}
$$

where $L_{p}^{*}, a_{p}^{*}$, and $b_{p}^{*}$ are the lightness, greenness-redness, and blueness-yellowness values of plasma-treated samples, and $L^{*}{ }_{c} a^{*}{ }_{c}$, and $b^{*}{ }_{c}$ are those of the control (untreated) sample.

\section{Statistical analysis}

The statistical analysis was performed using version 23 of the SPSS Statistics (IBM, USA). In this regard, the
ANOVA along with the Post Hoc-Duncan assay at a 0.95 confidence interval was used to detect significant differences between the mean values.

\section{Result and discussion}

\section{Liquid chromatography-mass spectrometry of pesticide residue}

Figure 3 represents the LC-MS chromatograms of control and plasma-treated samples. According to the data, a similar peak was identified at a retention time of $17.8 \mathrm{~min}$ for all the samples. These peaks have a similar intensity of about $4 \times 10^{8}$. Besides, no additional peaks were detected in either DBD or arc plasma-treated samples during 20 min of elution time. Therefore, neither arc nor DBD plasma process degraded the chlorpyrifos, and this pesticide resisted against these processes. It was expected that the plasma-generated reactive species, such as free radicals, ozone, and ions, affect the chemical structure of the chlorpyrifos. However, for the first time, the present investigation disclosed that this pesticide remained unchanged after plasma treatment. These new observations highlighted the importance of research in pesticide degradation by cold plasma. While the simple concept of pesticide degradation due to its exposure to plasma-generated reactive species is well-explained in the literature, research is needed in this area for an understanding of the key parameters and their effects on the decontamination process. Taking the present study as an example, the type of the plasma system can be considered as a key parameter. While DBD plasma systems have a general concept in producing plasma, the detail of their design, which varies depending on the supplier, can greatly affect its applicability for food processing (e.g., decontamination) (Gavahian et al., 2020). The same holds good for the arc plasma systems. Also, in the case of the arc systems, it should be noted that high temperatures of plasma gas may result in thermal degradation of pesticides, which may be wrongly interpreted as reactive species-induced degradation in some studies (Cengiz et al., 2015; Gavahian et al., 2019b). Besides, process parameters, including carrier gas composition, pressure, applied voltage, discharge distance, sample exposure mode (direct vs. indirect), can affect the performance of a plasma system for pesticide degradation.

Zhou et al. (2018) reported that the performance of plasma in removing pesticide residues from food materials was related to the type of plasma and the process conditions such as the processing time and the plasma voltage. Likewise, Sarangapani et al. (2016) assessed the efficacy of high voltage DBD plasma on three types of pesticides, namely, endosulfan, malathion, and dichlorvos. According to the authors, the efficiency of high-voltage 


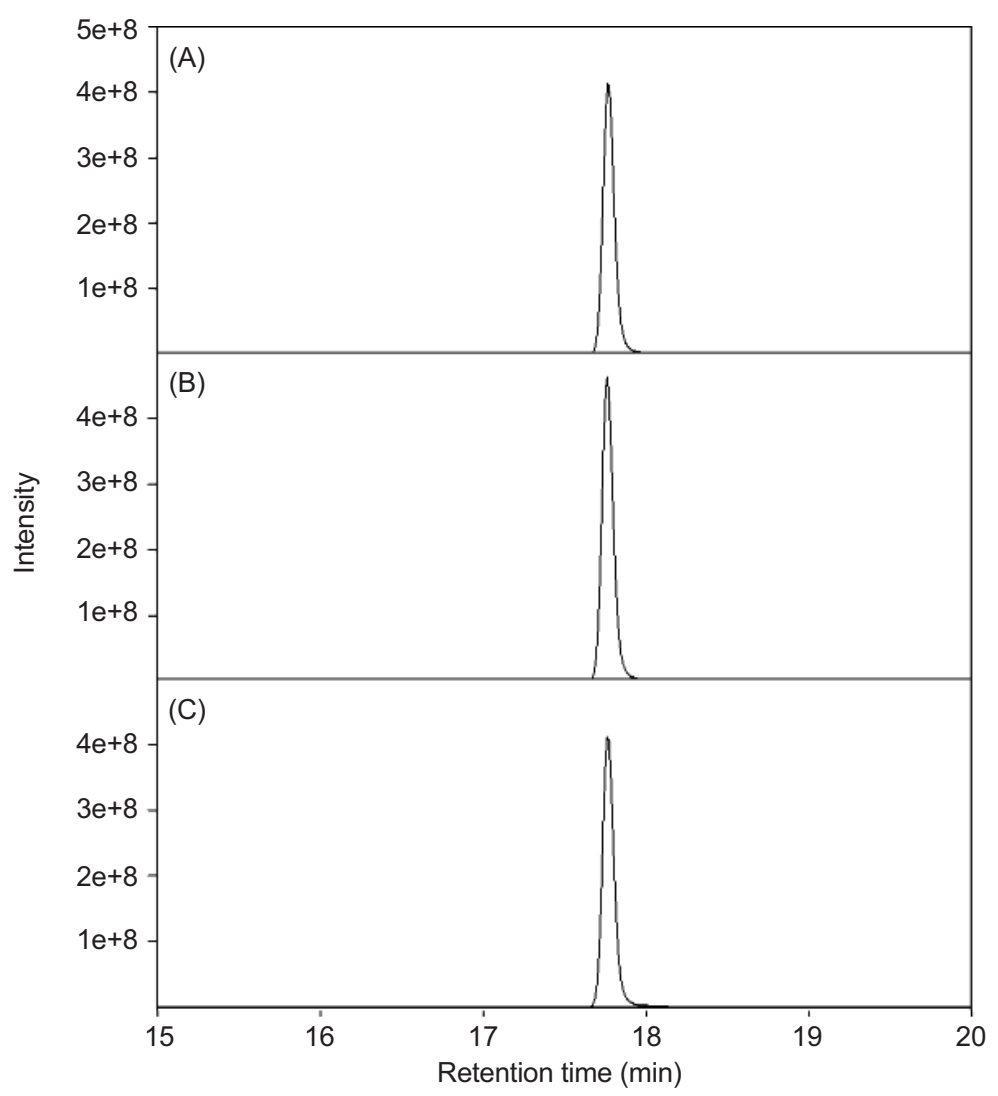

Figure 3. Liquid chromatography-mass spectrometry (LC-MS) chromatogram of control (A), arc plasma-treated (B), and dielectric barrier discharge (DBD) plasma-treated (C) samples.

plasma in pesticide degradation varied, depending on the type of pesticide. They reported that $2 \mathrm{~min}$ of $60 \mathrm{kV}$ plasma treatment resulted in $8.6,7.9$, and $4.2 \%$ decrease in the concentration of endosulfan, dichlorvos, and malathion, respectively. Therefore, different resistances to plasma conditions can be expected from different types of pesticides. Sarangapani et al. (2016) also showed that increasing both the input voltage and the treatment time resulted in better pesticide removal. For example, the input voltage of $80 \mathrm{kV}$ and the extended process time eliminated up to $80.0 \%$ of dichlorvos from the pesticide sample. On the other hand, they observed that even applying high voltage for an extended time could not produce pesticide-free products, which suggests that cold plasma was not a reliable technique for the production of pesticide-free products, which is in line with the findings of the present study. Moreover, it was previously explained that different concentrations of reactive species can be produced by different types of plasma and also under different plasma conditions (Gavahian et al., 2018; Sarangapani et al., 2018). Furthermore, nonoptimized cold plasma treatment was shown to be inefficient in removing unpleasant allergens from milk (Tammineedi et al., 2013). Therefore, the efficacy of cold plasma in the degradation of pesticide residue should be fully explored before the industrial adaptation of this emerging technique, especially regarding plasma type, process condition, and the sensitivity of the target pesticide to the plasma treatment. A comparison between the effects of various plasma processes on chlorpyrifos is presented in Table 2 . The type of plasma equipment and the process conditions are among the major effective parameters that should be considered in the plasma degradation of chlorpyrifos. It should also be noted that it should be the case for other technologies, such as Ultraviolet (UV), in spite of the promising results reported in the literature (Vasseghian et al., 2020).

\section{Variations in sample temperature}

Figure 4 represents fluctuations in the temperature of pesticide during $8 \mathrm{~min}$ of DBD and arc plasma treatments. While the temperature of samples remained steady in the DBD plasma system (due to the ability of this system in controlling the temperature), 8 min of arc plasma process altered the temperature of the pesticide sample from 30 to about $60^{\circ} \mathrm{C}$ at a rate of about $3.75^{\circ} \mathrm{C}$. $\mathrm{min}^{-1}$. Likewise, it was observed that 10-min of plasma processing of water increased the temperature of water 
Table 2. An overview of the effects of various plasma technologies on chlorpyrifos.

\begin{tabular}{|c|c|c|c|c|c|}
\hline Plasma device & Matrix & Process condition & $\begin{array}{c}\text { Maximum } \\
\text { degradation (\%) }\end{array}$ & Insight findings & Reference \\
\hline $\begin{array}{l}\text { Monopole } \\
\text { dielectric barrier } \\
\text { discharge }\end{array}$ & Apples & $\begin{array}{l}\text { - Plasma voltage: up to } 13 \mathrm{kV} \\
\text { - Process time: up to } 10 \mathrm{~min}\end{array}$ & 87 & $\begin{array}{l}\text { Plasma treatment significantly } \\
\text { decreased pesticide concentration }\end{array}$ & $\begin{array}{l}\text { Mousavi et al., } \\
2017\end{array}$ \\
\hline $\begin{array}{l}\text { Gliding discharge } \\
\text { plasma }\end{array}$ & Mango & $\begin{array}{l}\text { - Argon was the carrier gas } \\
\text { (flow rate: } 5 \mathrm{~L} / \mathrm{min} \text { ) }\end{array}$ & 63 & $\begin{array}{l}\text { Gliding discharge plasma was } \\
\text { introduced as an effective surface } \\
\text { decontamination for mango }\end{array}$ & $\begin{array}{l}\text { Phan et al., } \\
2018\end{array}$ \\
\hline $\begin{array}{l}\text { Dielectric barrier } \\
\text { discharge }\end{array}$ & Tomatoes & $\begin{array}{l}\text { - Plasma power: up to } 5 \mathrm{~W} \\
\text { - Process time: up to } 6 \mathrm{~min}\end{array}$ & 89 & $\begin{array}{l}\text { Dielectric barrier discharge plasma } \\
\text { was introduced as an effective sur- } \\
\text { face decontamination for tomatoes }\end{array}$ & $\begin{array}{l}\text { Ranjitha Gracy } \\
\text { et al., } 2019\end{array}$ \\
\hline $\begin{array}{l}\text { Dielectric barrier } \\
\text { discharge }\end{array}$ & Maze & $\begin{array}{l}\text { - Argon was the carrier gas } \\
\text { - Plasma power: up to } 25 \mathrm{~W} \\
\text { - Process time: up to } 1 \mathrm{~min}\end{array}$ & 91 & $\begin{array}{l}\text { Argon dielectric barrier discharge } \\
\text { treatment was introduced to be } \\
\text { effective in enhancing the corn } \\
\text { safety }\end{array}$ & $\begin{array}{l}\text { Feng et al., } \\
2019\end{array}$ \\
\hline
\end{tabular}

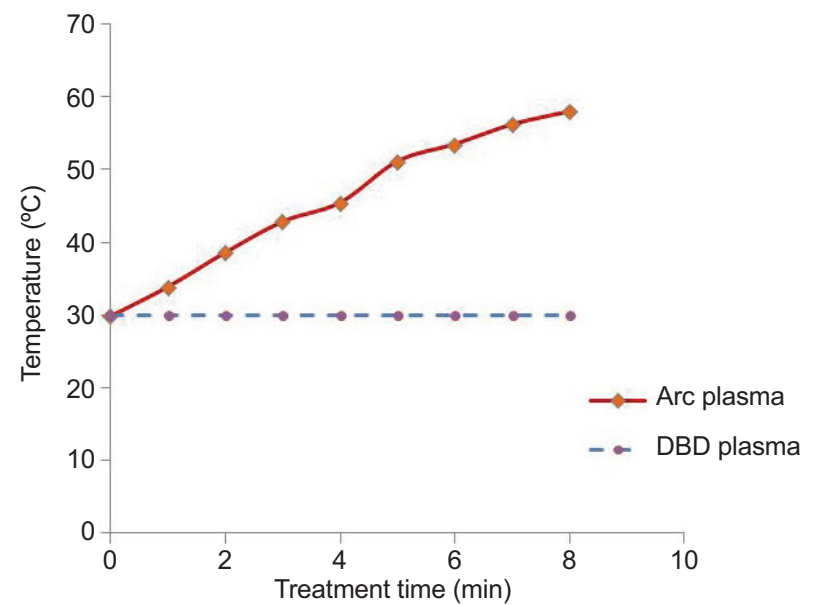

Figure 4. Variations in the temperature of chlorpyrifos during arc and dielectric barrier discharge (DBD) plasma treatments.

from 23 to $37^{\circ} \mathrm{C}$ (Ma et al., 2016). It should be noted that the temperature increase observed in the current investigation was also inefficient in pesticide degradation. It was previously explained that pesticides can stand mild temperatures (Amirahmadi et al., 2017; Kennedy and Mackie, 2018), which concurs with the observations in the present study.

\section{Physical constants}

The color parameters of the samples are presented in Table 3. According to the data, the plasma treatment did not significantly alter the lightness, blue-yellow, and green-red values of the sample. Researchers classified the overall color change $(\Delta \mathrm{E})$ value as great, well-visible, noticeable, slightly noticeable, and not noticeable when it ranged between $6.0-12.0,3.0-6.0,1.5-3.0,0.5-1.5$, and
Table 3. The effects of plasma treatments on the color parameters and refractive indexes of pesticides.

\begin{tabular}{lccc} 
& Control sample & DBD plasma & Arc plasma \\
\hline $\mathrm{Rl}^{*}$ & $1.3642^{\mathrm{a}} \pm 0.0001$ & $1.3642^{\mathrm{a}} \pm 0.0001$ & $1.3642^{\mathrm{a}} \pm 0.0001$ \\
$\mathrm{~L}^{*}$ & $20.64^{\mathrm{a}} \pm 0.99$ & $19.1^{\mathrm{a}} \pm 0.41$ & $20.29^{\mathrm{a}} \pm 0.13$ \\
$\mathrm{a}^{*}$ & $-0.36^{\mathrm{a}} \pm 0.03$ & $-0.39^{\mathrm{a}} \pm 0.05$ & $-0.37^{\mathrm{a}} \pm 0.02$ \\
$\mathrm{~b}^{*}$ & $-2.36^{\mathrm{a}} \pm 0.12$ & $-2.21^{\mathrm{a}} \pm 0.05$ & $-2.33^{\mathrm{a}} \pm 0.05$ \\
$\Delta \mathrm{E}$ & - & $1.56^{\mathrm{a}} \pm 1.21$ & $1.09^{\mathrm{a}} \pm 0.35$ \\
\hline
\end{tabular}

${ }^{*} \mathrm{RI}$ : Refractive index; L*: lightness; $\mathrm{a}^{*}$ : greenness-redness; $\mathrm{b}^{*}$ : blueness-yellowness; $\Delta \mathrm{E}$ : overall color differences. ${ }^{* *}$ Data are presented as Mean \pm Standard deviation. $\mathrm{DBD}$, dielectric barrier discharge.

0-0.5, respectively (Cserhalmi et al., 2006). It was previously explained that $\Delta \mathrm{E}$ values above 3.0 are obvious to the human eyes (Puligundla et al., 2018). The data in Table 3 suggested that the variations in the overall color of the samples were not significant, considering the standard deviations of the reported values. Arc and DBD plasma treatments resulted in overall color change values of $1.1 \pm$ 0.4 and $1.6 \pm 1.2$, respectively. Similar to the observations in this study, Dasan et al. (2018) reported that plasma treatment did not significantly affect the color of the eggshell samples (Dasan et al., 2018). Similar results were reported by Puligundla et al. (2018) for plasma-treated Gwamegi samples (Puligundla et al., 2018). Furthermore, Phan et al. (2018) disclosed that $10 \mathrm{~min}$ of arc plasma did not alter the color of a pesticide-contaminated sample, and all the overall color change $(\Delta E)$ was about 2.5. Likewise, the plasma process did not alter the refractive index of the pesticide solution, and all the samples had a similar refractive index of 1.3642 . This finding was in line with the result of the LC-MS study. Similar physical properties of samples can be expected as arc and DBD plasma treatments did not alter the chemical structure of 
the samples. It should be noted that the decontamination efficiency and effects of plasma processing on the quality parameters of food samples should be assessed when an appropriate plasma system is designed and developed for degrading agrochemical residues of foods. These are among the key considerations for developing an effective plasma system that can be implemented in the industry.

\section{Conclusion}

The effects of the two types of plasma devices, namely, DBD and arc, on a major pesticide residue of agricultural products, that is, chlorpyrifos, were investigated. LC-MS results revealed that the chlorpyrifos pesticide, under the experimental conditions used in this study, had high resistance against plasma treatments, i.e., neither arc nor DBD plasma treatments degraded this hazardous chemical. In spite of the promising decontamination effects of plasma reported in the literature (Table 2), the findings of this study can be considered prior to industrial adaptation of cold plasma for the production of pesticide-free products. Therefore, the commercial application of cold plasma for the removal of pesticides requires critical research and careful evaluation. Other aspects, such as selecting the appropriate type of plasma equipment, optimization of the process parameter, understanding the resistance of different types of pesticides against cold plasma, and further upscaling studies, should be considered. The use of plasma treatment to remove hazardous chemicals (e.g., pesticide pollutions) from products (e.g., fruits) with a waxy shell has not been well investigated in the literature. Therefore, the efficiency of plasma treatments in degrading other types of pesticides in such products can be considered further in prospective studies. Besides, the type of pesticide degrades are highly dependent on several parameters, such as plasma generation device, plasma power, plasma exposure time, and the carrier gas composition which influence the type and the concentration of the reactive species (e.g., reactive oxygen species) and the overall efficiency of plasma-induced degradation for a particular pesticide. Hence, the effects of other carrier gases, particularly $\mathrm{O}_{3}$, in plasma treatment should be examined to have a better understanding of the ability of cold plasma in removing residual toxins.

\section{Acknowledgments}

The authors would like to thank the College of Agriculture of National Pingtung University of Science and Technology (NPUST) of Taiwan for supporting plasma research. Also, the support of Food Industry Research and Development Institute of Taiwan is appreciated.

\section{References}

Albasher, G., Albrahim, T., Alsultan, N., Alfaraj, S., Alharthi, M.S., Kassab, R.B. and Abdel Moneim, A.E., 2020. Red beetroot extract mitigates chlorpyrifos-induced reprotoxicity associated with oxidative stress, inflammation, and apoptosis in rats. Environmental Science and Pollution Research 27: 3979-3991. https://doi.org/10.1007/s11356-019-07009-6

Ali, S.N., Baqar, M., Mumtaz, M., Ashraf, U., Anwar, M.N., Qadir, A., Ahmad, S.R., Nizami, A.S. and, Jun, H., 2020. Organochlorine pesticides in the surrounding soils of POPs destruction facility: source fingerprinting, human health, and ecological risks assessment. Environmental Science and Pollution Research 27: 73287340. https://doi.org/10.1007/s11356-019-07183-7

Amirahmadi, M., Kobarfard, F., Pirali-Hamedani, M., Yazdanpanah, H., Rastegar, H., Shoeibi, S. and Mousavi Khaneghah, A., 2017. Effect of Iranian traditional cooking on fate of pesticides in white rice. Toxin Reviews 36: 177-186. https://doi.org/10.1080/15569543.2017.1301956

Anderson, T., Liu, J., McMurry, S. and Pope, C., 2018. Comparative in vitro and in vivo effects of chlorpyrifos oxon in the outbred CD-1 mouse (Mus musculus) and great plains toad (Anaxyrus cognatus). Environmental Toxicology and Chemistry 37: 18981906. https://doi.org/10.1002/etc.4139

Cengiz, M.F., Catal, M., Erler, F. and Bilgin, K., 2015. The effects of heat treatment on the degradation of the organophosphate pesticide chlorpyrifos-ethyl in tomato homogenate. Quality Assurance and Safety of Crops \& Foods 7: 537-544. https://doi. org/10.3920/QAS2013.0301

Cserhalmi, Z., Sass-Kiss, Á., Tóth-Markus, M. and Lechner, N., 2006. Study of pulsed electric field treated citrus juices. Innovative Food Science and Emerging Technologies 7: 49-54. https://doi.org/10.1016/j.ifset.2005.07.001

Dasan, B.G., Yildirim, T. and Boyaci, I.H., 2018. Surface decontamination of eggshells by using non-thermal atmospheric plasma. International Journal of Food Microbiology 266: 267-273. https://doi.org/10.1016/j.ijfoodmicro.2017.12.021

EPA, 2016. Chlorpyrifos: revised human health risk assessment for registration review. United States Environmental Protection Agency. DP No. D436317. Washington, DC, United States.

EPA, 2011a. Revised chlorpyrifos preliminary reg review drinking water assessment. DP No. D368388-389480. Washington, DC, United States.

EPA, 2011b. Preliminary human health risk assessment for registration review. DP No. D388070. Washington, DC, United States.

Farkhondeh, T., Amirabadizadeh, A., Samarghandian, S. and Mehrpour, O., 2020. Impact of chlorpyrifos on blood glucose concentration in an animal model: a systematic review and meta-analysis. Environmental Science and Pollution Research 27: 2474-2481. https://doi.org/10.1007/s11356-019-07229-w

Feng, X., Ma, X., Liu, H., Xie, J., He, C. and Fan, R., 2019. Argon plasma effects on maize: pesticide degradation and quality changes. Journal of the Science of Food and Agriculture 99: 5491-5498. https://doi.org/10.1002/jsfa.9810

Foong, S.Y., Ma, N.L., Lam, S.S., Peng, W., Low, F., Lee, B.H.K., Alstrup, A.K.O. and Sonne, C., 2020. A recent global review 
of hazardous chlorpyrifos pesticide in fruit and vegetables: prevalence, remediation and actions needed. Journal of Hazardous Materials 400: 123006. https://doi.org/10.1016/j. jhazmat.2020.123006

Gavahian, M., Chu, Y.-H. and Farahnaky, A., 2019a. Effects of ohmic and microwave cooking on textural softening and physical properties of rice. Journal of Food Engineering 243: 114-124. https:// doi.org/10.1016/j.jfoodeng.2018.09.010

Gavahian, M., Chu, Y.H., Mousavi Khaneghah, A., Barba, F.J. and Misra, N.N., 2018. A critical analysis of the cold plasma induced lipid oxidation in foods. Trends in Food Science \& Technology 77: 32-41. https://doi.org/10.1016/j.tifs.2018.04.009

Gavahian, M. and Cullen, P.J., 2020. Cold plasma as an emerging technique for mycotoxin-free food: efficacy, mechanisms, and trends. Food Reviews International 36: 193-214. https://doi.org/ 10.1080/87559129.2019.1630638

Gavahian, M., Farahnaky, A., Javidnia, K. and Majzoobi, M., 2012. Comparison of ohmic-assisted hydrodistillation with traditional hydrodistillation for the extraction of essential oils from Thymus vulgaris L. Innov. Innovative Food Science and Emerging Technologies 14: 85-91. https://doi.org/10.1016/j. ifset.2012.01.002

Gavahian, M. and Khaneghah, A.M., 2020. Cold plasma as a tool for the elimination of food contaminants: recent advances and future trends. Critical Reviews in Food Science and Nutrition 60: 1581-1592. https://doi.org/10.1080/10408398.20 19.1584600

Gavahian, M., Peng, H.J. and Chu, Y.H., 2019b. Efficacy of cold plasma in producing Salmonella-free duck eggs: effects on physical characteristics, lipid oxidation, and fatty acid profile. Journal of Food Science and Technology 56: 5271-5281. https://doi. org/10.1007/s13197-019-03996-z

Gavahian, M., Sheu, F.H., Tsai, M.J. and Chu, Y.H., 2020. The effects of dielectric barrier discharge plasma gas and plasma-activated water on texture, color, and bacterial characteristics of shiitake mushroom. Journal of Food Processing and Preservation 44 (1): e14316. https://doi.org/10.1111/jfpp.14316

Guo, Y.W., Xie, X., Wang, B., Zhang, Y.Y., Xie, K.Z., Bu, X.N., Liu, C.J., Zhang, T., Zhang, G.X., Liu, X.Z. and Dai, G.J., 2020. The establishment of a practical method for the determination of piperazine residues using accelerated solvent extraction and UHPLC-FLD. Quality Assurance and Safety of Crops \& Foods 12: 28-39. https://doi.org/10.15586/QAS2019.657

Halimatunsadiah, A.B., Norida, M., Omar, D. and Kamarulzaman, N.H., 2016. Application of pesticide in pest management: the case of lowland vegetable growers. International Food Research Journal 23: 85-94.

Heshmati, A., Komacki, H.A., Nazemi, F. and Mousavi Khaneghah, A., 2020. Persistence and dissipation behavior of pesticide residues in parsley (Petroselinum crispum) under field conditions. Quality Assurance and Safety of Crops \& Foods 12: 55-65. https://doi.org/10.15586/qas.v12i3.755

Jawale, R.H. and Gogate, P.R., 2016. Combined treatment approaches based on ultrasound for removal of triazophos from wastewater. Ultrasonics Sonochemistry 40: 89-96. https://doi. org/10.1016/j.ultsonch.2017.02.019
Kennedy, E.M. and Mackie, J.C., 2018. Mechanism of the thermal decomposition of chlorpyrifos and formation of the dioxin analog, 2,3,7,8-tetrachloro-1,4-dioxino-dipyridine (TCDDpy). Environmental Science \& Technology 52: 7327-7333. https:// doi.org/10.1021/acs.est.8b01626

Ma, R., Yu, S., Tian, Y., Wang, K., Sun, C., Li, X., Zhang, J., Chen, K. and Fang, J., 2016. Effect of non-thermal plasma-activated water on fruit decay and quality in postharvest Chinese bayberries. Food and Bioprocess Technology 9: 1825-1834. https://doi. org/10.1007/s11947-016-1761-7

Mousavi, S.M., Imani, S., Dorranian, D., Larijani, K. and Shojaee, M., 2017. Original Article. Effect of cold plasma on degradation of organophosphorus pesticides used on some agricultural products. Journal of Plant Protection Research 57: 26-35. https://doi. org/10.1515/jppr-2017-0004

Pandiselvam, R., Kaavya, R., Jayanath, Y., Veenuttranon, K., Lueprasitsakul, P., Divya, V., Kothakota, A. and Ramesh, S.V., 2020. Ozone as a novel emerging technology for the dissipation of pesticide residues in foods - a review. Trends in Food Science \& Technology 97: 38-54. https://doi.org/10.1016/j.tifs.2019.12.017

Phan, K.T.K., Phan, H.T., Boonyawan, D., Intipunya, P., Brennan, C.S., Regenstein, J.M. and Phimolsiripol, Y., 2018. Non-thermal plasma for elimination of pesticide residues in mango. Innovative Food Science and Emerging Technologies 48: 164-171. https://doi.org/10.1016/j.ifset.2018.06.009

Puligundla, P., Choi, S. and Mok, C., 2018. Microbial decontamination of Gwamegi (semi-dried Pacific Saury) using corona discharge plasma jet, including physicochemical and sensory evaluation. Journal of Aquatic Food Product Technology 27: 274-283. https://doi.org/10.1080/10498850.2017.1347592

Ranjitha Gracy, T.K., Gupta, V. and Mahendran, R., 2019. Influence of low-pressure nonthermal dielectric barrier discharge plasma on chlorpyrifos reduction in tomatoes. Journal of Food Process Engineering 42: e13242. https://doi.org/10.1111/jfpe.13242

Razzaghi, N., Ziarati, P., Rastegar, H., Shoeibi, S., Amirahmadi, M., Conti, G.O., Ferrante, M., Fakhri, Y. and Mousavi Khaneghah, A., 2018. The concentration and probabilistic health risk assessment of pesticide residues in commercially available olive oils in Iran. Food and Chemical Toxicology 120: 32-40. https://doi. org/10.1016/j.fct.2018.07.002

Regulations, C. of F., 2020. 40 CFR 180.342 - chlorpyrifos; tolerances for residues [WWW Document]. Available at: https:// www.law.cornell.edu/cfr/text/40/180.342\#: :text=(3) A tolerance of 0.1 , as a result of the

Sarangapani, C., Misra, N.N., Milosavljevic, V., Bourke, P., O’Regan, F. and Cullen, P.J., 2016. Pesticide degradation in water using atmospheric air cold plasma. Journal of Water Process Engineering 9: 225-232. https://doi.org/10.1016/j. jwpe.2016.01.003

Sarangapani, C., Patange, A., Bourke, P., Keener, K. and Cullen, P.J., 2018. Recent advances in the application of cold plasma technology in foods. Annual Review of Food Science and Technology 9: 609-629. https://doi.org/10.1146/annurev-food-030117-012517

Serefoglu, C. and Serefoglu, S., 2016. Consumer fair prices for less pesticide in potato. Italian Journal of Food Science 28: 107-120. https://doi.org/10.14.674/1120-1770/ijfs.v464. 
Shoeibi, S., Amirahmadi, M., Rastegar, H., Khosrokhavar, R., Khaneghah, A.M. (2013). An applicable strategy for improvement recovery in simultaneous analysis of 20 pesticides residue in tea. Journal of Food Science 78(5): T792-6. https://doi: 10.1111/1750-3841.12100.

Tammineedi, C.V.R.K., Choudhary, R., Perez-Alvarado, G.C. and Watson, D.G., 2013. Determining the effect of UV-C, high intensity ultrasound and nonthermal atmospheric plasma treatments on reducing the allergenicity of $\alpha$-casein and whey proteins. LWT - Food Science and Technology 54: 35-41. https://doi. org/10.1016/j.lwt.2013.05.020

Vasseghian, Y., Moradi, M., Pirsaheb, M., Khataee, A., Rahimi, S., Badi, M.Y. and Mousavi Khaneghah, A., 2020. Pesticide decontamination using UV/ferrous-activated persulfate with the aid neuro-fuzzy modeling: a case study of Malathion. Food Research International 137: 109557. https://doi.org/10.1016/j. foodres.2020.109557

Vigneshwaran, S., Preethi, J. and Meenakshi, S., 2019. Removal of chlorpyrifos, an insecticide using metal free heterogeneous graphitic carbon nitride ( $\mathrm{g}-\mathrm{C} 3 \mathrm{~N} 4$ ) incorporated chitosan as catalyst: photocatalytic and adsorption studies. International Journal of Biological Macromolecules 132: 289-299. https://doi. org/10.1016/j.ijbiomac.2019.03.071

Zhou, R., Zhou, R., Yu, F., Xi, D., Wang, P., Li, J., Wang, X., Bazaka, K. and Ostrikov, K. K. (2018). Removal of organophosphorus pesticide residues from Lycium barbarum by gas phase surface discharge plasma. Chemical engineering journal, 342, 401-409. https://doi.org/10.1016/j.cej.2018.02.107 